\title{
Validity of Gray Scale Sonography along with Color Doppler Spectral Analysis for the detection of Malignant Breast Tumour
}

\author{
Showkat Ara', Sabina Jesmin², AFM Arshedi Sattar ${ }^{3}$, SM Quamrul Akhter', \\ Waseka Akhter Jahan ${ }^{5}$, AKM Golam Kabir ${ }^{6}$, Syed Md. Sazzad Kamal ${ }^{7}$
}

\begin{abstract}
${ }^{1}$ Assistant Professor, Department of Neuroradiology \& Imaging, National Institute of Neurosciences \& Hospital, Dhaka, Bangladesh;
${ }^{2}$ Assistant Professor, Department of Pharmacology, National Institute of Neurosciences \& Hospital, Dhaka, Bangladesh;

${ }^{3}$ Assistant Professor, Department of Microbiology, National Institute of Neurosciences \& Hospital, Dhaka, Bangladesh;

${ }^{4}$ Assistant Professor, Department of Surgery, ShaheedSuhrawardy Medical College, Dhaka, Bangladesh; ${ }^{5}$ Associate

Professor, Department of Biochemistry, National Institute of Neurosciences \& Hospital, Dhaka, Bangladesh;

${ }^{6}$ Assistant Professor, Department of Neuroradiology \& Imaging, National Institute of Neurosciences\&

Hospital, Dhaka, Bangladesh; ${ }^{7}$ Senior Consultant (Radiology \& Imaging),

Jessor General Hospital, Jessor, Bangladesh
\end{abstract}

[Received: 21 January 2016; Revised: 6March 2016; Accepted: 11December 2016; Published: 1 January 2017]

\begin{abstract}
Background: Detection of mass in the breastis very essential for the early treatment. Objective: The purpose of the present study was to validate the Doppler sonography to detect the pathological lesions of breast. Methodology: This cross sectional study was carried out in the Department of Radiology and Imaging in collaboration with the Department of Surgery and Department of Pathology at Banghabandhu Sheikh Mujib Medical University (BSMMU), Dhaka from July 2008 to June 2009 for a period of one (01) year. Clinically suspected women with breast mass who were attended in the OPD or inpatient department were selected purposively as study population. All the patients were examined by 2-D Real-Time B-Mode Ultrasonography by using high frequency $(7.5 \mathrm{MHz})$ linear transducer. Blood flow was studied using Duplex sonography in which Gray scale 2D sonography was combined with Pulsed Doppler. Test of validity was done for color Doppler Sonographic findings in evaluation of benign and malignant breast lesion. Result: A total number of 50 cases were recruited for this study. Out of 50 cases, 25 cases true positive, 1 false negative, 2 false positive, 22 true negative confirmed by histopathology. Here sensitivity and specificity of color Doppler ultrasonography are $92.59 \%$ and $86.95 \%$ respectively. Here accuracy of color Doppler study is $90.0 \%$ and the positive predictive value was $89.28 \%$ and negative predictive value was $90.9 \%$. Conclusion: Color Doppler Ultrasonography is a useful imaging method in the differentiation between benign and malignant breast masses. [Journal of National Institute of Neurosciences Bangladesh, 2017;3(1): 10-13]
\end{abstract}

Keywords: Validity; gray scale; sonography; color doppler; spectral analysis; malignant breast tumour

Correspondence: Dr. ShowkatAra, Assistant Professor, Department of Neuroradiology \& Imaging, National Institute of Neurosciences \& Hospital, Dhaka, Bangladesh; Email: munny199@gmail.com ; Cell no.: +8801711708008

Conflict of Interest: The authors declare that they have no competing interest.

Contributions to Authors: SA, AKMGK\& SMSK were involved in protocol preparation, data collection and data analysis. SJ, AFMAS \& SMQA were contributed for the manuscript preparation. MAY \& WAJ were revised the manuscript.

Funding: This research project was not funded by any group or any institute on.

How to cite this article: Ara S, Jesmin S, Sattar AFMA, Akhter SMQ,Jahan WA, Kabir AKMG, Kamal SMS. Validity of Gray Scale Sonography along with Color Doppler Spectral Analysis for the detection of Malignant Breast Tumour. J NatlInstNeurosci Bangladesh, 2017;3(1): 10-13

Copyright: (C2017 Ara et al. Published by Journal of National Institute of Neurosciences Bangladesh. This article is published under the Creative Commons CC BY-NC License (https://creativecommons.org/licenses/by-nc/4.0/). This license permits use, distribution and reproduction in any medium, provided the original work is properly cited, and is not used for commercial purposes.

\section{Introduction}

Breast lesions particularly breast cancer causes some $20.0 \%$ of cancer death among females ${ }^{1}$. Breast cancer is the commonest cause of death in middle-aged women in western countries ${ }^{2}$. Currently, one of every nine women in United States of America would develop breast cancer in their life timeand virtually remain stable over the past thirty years, now being about 27 per one $\operatorname{lac}^{3}$. In 
developing countries, it accounts for 1.0 to $3.0 \%$ of death $^{4}$. Specifically, in Bangladesh, breast lesions particularly breast cancer is common clinical problem. In Bangladesh remarkable increase of breast cancer has occurred in current year.

Color Doppler Ultrasonography is very useful in the differentiation between benign and malignant breast masses. The criteria that the presence of intratumoral or peripheral blood flow on Color Doppler indicated the existence of malignant disease and the absence of such flow in benign disease yielded promising results in early research. However, the detection of vessels on the inside of a breast nodule is significantly linked with malignancy ${ }^{5}$.Evaluation of the spatial distribution of vessels and ability to resolve spectral analysis may add valuable information to the imaging based diagnostic work-up of indeterminate Solid breast lesions. Breast malignancies have higher resistance indices assessed by color-coded Doppler ultrasound than benign lesions6.Choi et $\mathrm{al}^{1}$ also attempted to evaluate the significance of resistive index (RI) in differentiating between benign and malignant breast lesions on Color Doppler Examination. The purpose of this study was to assess the overall diagnostic accuracy of color Doppler US and its real diagnostic contribution as an adjunct to palpation and aspiration cytology to identify the benign and malignant breast lesion.

\section{Methodology}

This cross sectional study was carried out in the Department of Radiology and Imaging in collaboration with the Department of Surgery and Department of Pathology at Banghabandhu Sheikh Mujib Medical University (BSMMU), Dhaka from July 2008 to June 2009 for a period of one (01) year.Fifty consecutively collected patients with palpable breast lesions were admitted in the surgery units of BSMMU they were diagnosed clinically as having solid breast lumps. The objective of the study was discussed in details with the patients before their decision to enroll themselves into the study. A detailed clinical history was taken from the patients about their symptoms like lump, duration of complains, pain, nipple discharge, nipple retraction etc. Relevant physical examinations were also done in all the cases. They underwent gray scale sonography followed by Power Doppler study with spectral analysis.Presence of intralesional vessels and their distribution pattern were evaluated first with Power Doppler Imaging (PDI), spectral tracing were also recorded to obtain Resistive Index (Rl) from the intralesional vessels. Malignancy of Breast lesions were detected pre-operatively. The findings were also interpreted first by the investigator and to eliminate bias the findings were confirmed by a radiologist of the department.Excision biopsy or mastectomy was done in all cases. Their postoperative findings were noted and correlated with sonological findings. Tissues of surgically removed tumors were sent to the pathology department. Their histopathology reports were collected and were then correlated with the gray scale sonography and Doppler findings. All this information was collected in a pre-designed data collection sheet.Statistical analysis was done by using SPSS version 21.0 for Windows. Assumptions of normality and homogeneity of variance were initially checked. The differences between two groups was assessed with using $\mathrm{t}$ test or Mann-Whitney U test, as appropriate. Categorical variables were expressed as proportions and was compared with using Chi-square test. Their sensitivity, specificity, positive predictive value (PPV), negative predictive value (NPV) were calculated. A value of $p<0.05$ was considered statistically significant for all tests.

\section{Results}

Out 50 cases 28 patients diagnosed as benign and 22 cases were diagnosed as malignant after performing excisional biopsy. In this study, it was found that the upper and outer quadrant of the malignant and benign lesions was most common site of color Doppler abnormalities, which were $25.0 \%$ in right side and $33.3 \%$ in left side in malignant lesion. In benign lesions found upper and outer quadrant $34.21 \%$ and $18.42 \%$ in right and left side respectively (Table 1).

Table 1: Distribution of all the parameters compared to Histopathological report

\begin{tabular}{|c|c|c|c|}
\hline Criteria & Malignant & Benign & P Value \\
\hline \multicolumn{4}{|l|}{ Size } \\
\hline$\cdot>1.4 \mathrm{~cm}$ & $18(75 \%)$ & $18(69.24 \%)$ & $0.001^{\mathrm{s}}$ \\
\hline - $<1.4 \mathrm{~cm}$ & $06(25 \%)$ & $8(30.76 \%)$ & \\
\hline Margin & & & \\
\hline - Irregular & $16(80 \%)$ & $10(38.47 \%)$ & $0.001^{\mathrm{s}}$ \\
\hline - Regular & $4(20 \%)$ & $16(61.38 \%)$ & \\
\hline Internal Echo & & & I \\
\hline • Hypoechoic & $4(16.66 \%)$ & $18(69.23 \%)$ & $0.001^{\mathrm{s}}$ \\
\hline - Hyperechoic & $0(0 \%)$ & $5(19.23 \%)$ & \\
\hline - Heterogenous & $20(83.34 \%)$ & $3(11.54 \%)$ & \\
\hline Calcification & & & \\
\hline - Present & $18(75 \%)$ & $3(11.53 \%)$ & $0.001^{\mathrm{s}}$ \\
\hline - Absent & $6(25 \%)$ & $23(88.47 \%)$ & \\
\hline $\begin{array}{l}\text { Flow Pattern } \\
\text { - Peripheral }\end{array}$ & $22(88 \%)$ & $20(80 \%)$ & $0.001^{\mathrm{s}}$ \\
\hline $\begin{array}{l}\text { - Central } \\
\text { R.I }\end{array}$ & $3(12 \%)$ & $5(20 \%)$ & \\
\hline$\cdot>0.7$ & $23(91.66 \%)$ & $1(97.36 \%)$ & $0.426^{\mathrm{ns}}$ \\
\hline$\bullet<0.7$ & $4(8.33 \%)$ & $22(2.63 \%)$ & \\
\hline
\end{tabular}

R.I = Resistive Index 
Twenty five cases found truly malignant (true $+v e$ ) and 2 (two) cases were found benign (false -ve) as confirmed by histopathology; while of the 22 benign cases (US diagnosis), 20 were found benign (true -ve) as detected by FNAC and 2 (two) were found malignant (false -ve) which was confirmed by excisional biopsy. So, finally 28 cases were diagnosed malignant and 22 cases were benign (Table 2).

Table 2: Comparison between color Doppler Sonographic and Histopathological findings in evaluation of benign and malignant breast lesion

\begin{tabular}{lccc}
\hline $\begin{array}{l}\text { Gray Scale } \\
\text { along with }\end{array}$ & Histopathological Diagnosis for Malignancy & Total \\
\cline { 2 - 3 } Color Doppler & Positive & Negative & \\
\hline Malignant & 25 & 2 & 28 \\
Benign & 2 & 20 & 22 \\
Total & $\mathbf{2 7}$ & $\mathbf{2 3}$ & $\mathbf{5 0}$ \\
\hline
\end{tabular}

Validity of Gray Scale along with Color Doppler Sonography and histopathological findings were correlated by calculating Sensitivity, Specificity, Accuracy, Positive and Negative Predictive Values by using standard formula (Table 3).

Table 3: Validity of Gray Scale along with Color Doppler Sonography

\begin{tabular}{lc}
\hline Validity Test & Percentage \\
\hline Sensitivity & 92.59 \\
Specificity & 86.95 \\
Accuracy & 90 \\
Positive Predictive Values & 89.28 \\
Negative Predictive Values & 90.90 \\
\hline
\end{tabular}

\section{Discussion}

Ultrasonography in gray scale along with Doppler spectral analysis has been shown to be more effective modality in detection breast malignancy ${ }^{7}$. Color Doppler spectral analysis along with gray scale evaluation has become an important investigation and is considered as most important complementary method to mammography. Thus it could be concluded that Gray scale sonography along with Doppler spectral imaging increase chance of detection of malignancy $^{8}$. A resistive index of $>0.70$ is highly suggesting malignant lesion. Due to some overlapping of the range of resistive indexbetween benign and malignant cases, it may not be diagnostic in any single patient but it is extremely helpful in evaluation of false-negative cases evaluated on gray scale.

This comparison study was carried out in the department of Radiology and Imaging at BSMMU hospital in collaboration with the Departments of Surgery and Pathology Department of BSMMU during the period ofJuly 2008 to June 2009. Preoperative detection of breast malignancy by Doppler spectral analysis along with Gray scale sonography and its validity by determining sensitivity, specificity, accuracy, positive predictive value and negative predictive value. The age of patients ranged from 25 to 69 years. They were divided into 5 age groups. Maximum numbers of patients with solid breast lesions were found in the 50-59 years age group. The mean age was 51.2 years with standard error of mean (SE) \pm 1.5 years in the whole study patients. The mean $( \pm \mathrm{SE})$ of $\mathrm{Rl}$ values in benign and malignant solid lesions of breast were $0.61 \pm 0.04$ and $0.83 \pm 0.03$ respectively. The difference was statistically highly significant $(\mathrm{P}<0.001)$. Five benign lesions were found to have a RI value more than 0.70 . Histopathology reports were collected. Among the 50 patients $46 \%$ (23 cases) were proved to be benign lesions and 54\% (27 cases) were diagnosed as malignant lesions. Combined gray scale and Doppler findings evaluated. 28(56\%) cases were suspected as malignant and rest 22(44\%) cases were suspected as benign. Validity of the combined modality was measured by correlation with histopathological findings. Sensitivity, specificity, accuracy, positive predictive value (PPV) and negative predictive value (NPV) were $92.59 \%, 86.95 \%, 90 \%$, $89.28 \%$ and $90.90 \%$ respectively.

Twenty five cases found truly malignant (true $+v e$ ) and 2 (two) cases were found benign (false -ve) as confirmed by histopathology; while of the 22 benign cases (US diagnosis), 20 were found benign (true -ve) as detected by FNAC and 2 (two) were found malignant (false -ve) which was confirmed by excisional biopsy. So, finally 28 cases were diagnosed malignant and 22 cases were benign. The study findings indicate that Gray scale sonography along with Doppler spectral analysis is more sensitive, specific and accurate diagnostic tool then they used as a single modality in detection of malignant breast lesions.

Color Doppler ultrasonography can detect breast mass very early due to visualization of blood flow pattern of very small mass ${ }^{10}$. It can contribute to the survival benefit obtained by early breast cancer detection. For developing country like us color Doppler ultrasonography can be an easy, non-ionizing, non-invasive, time relieving, low cost diagnostic tool which can reduce unnecessary biopsies and surgical procedures and thus reducing morbidity and financial burden to the patient ${ }^{11}$. 
Limitation of the study were short period, small sample size, inflammatory lesions in breast that give increase RI index.Gray scale, color and power Doppler sonogrpahy and measurement of resistive index- all were performed by a single radiologist of the department, so there was chance of bias.

\section{Conclusion}

Doppler spectral analysis along with Gray scale sonography of solid breast lesions is sensitive, specific and accurate modality in detecting malignant solid breast lesions. So, it can be concluded that Doppler spectral analysis along with Gray scale sonography can be used as a sensitive diagnostic tool in the detection of malignant solid breast lesions. However, further research on this subject may be encouraged on large number of patients in multiple tertiary levels.

\section{References}

1. Choi HY, Kim HY, Baek SY, Kang BC, Lee SW. Significance of resistive index in color dopplerultrasonogram. Clinical imaging. 1999 Sep 1;23(5):284-8

2. Cotran RS, Kumar V, Collins T (editors), 6thEdn, Robbins basis of disease WBSaunders, Philadelphia, 2000, pp. 1119-1152
3. Fornage BD, Sneige N, Faroux MJ, Andry E. Sonographic appearance and ultrasound-guided fine-needle aspiration biopsy of breast carcinomas smaller than $1 \mathrm{~cm} 3$. Journal of ultrasound in medicine. 1990;9(10):559-68

4. Zhi H, Ou B, Luo BM, Feng X, Wen YL, Yang HY. Comparison of ultrasound elastography, mammography, and sonography in the diagnosis of solid breast lesions. Journal of ultrasound in medicine. 2007;26(6):807-15

5. del Cura JL, Elizagaray E, Zabala R, Legórburu A, Grande D. The use of unenhanced Doppler sonography in the evaluation of solid breast lesions. American Journal of Roentgenology. 2005;184(6):1788-94

6. Youssefzadeh S, Eibenberger K, Helbich T, Jakesz R, Wolf G. Use of resistance index for the diagnosis of breast tumours. Clinical radiology. 1996 Jun 1;51(6):418-20.

7. Moon WK, Im JG, Noh DY, Han MC. Non-palpable breast lesions: evaluation with power Doppler US and a microbubble contrast agent —initial experience. Radiology. 2000;217(1):240-6 8. Standring S. Breast. In: Gray's Anatomy. 39thedn. Elsevier Churchill Livingstone.2005, pp 969-975

9. Sainsbury RC. The Breast. In: Bailey \& Love's Short Practice of Surgery. Russel RCG, Williams NS, Bulstrode CJK (Editors), 24thedn. Arnold, Edinburgh, 2004, pp824-846

10. Chen DR, Chang RF, Kuo WJ, Chen MC, Huang YL. Diagnosis of breast tumors with sonographic texture analysis using wavelet transform and neural networks. Ultrasound in Medicine and Biology. 2002;28(10):1301-10.

11. Huang YL, Wang KL, Chen DR. Diagnosis of breast tumors with ultrasonic texture analysis using support vector machines. Neural Computing \& Applications. 2006;15(2):164-9 